\title{
AC 2011-2485: STUDENT LEARNING MODULES IN TRIGONOMETRY AND INTEGRAL CALCULUS USING LEGO MINDSTORMS NXT
}

\section{Byron L Newberry, Oklahoma Christian University}

Dr. Byron Newberry is Professor and Chair of Mechanical Engineering at Oklahoma Christian University. He holds a B.S.M.E. degree from Oklahoma Christian University and M.S. and Ph.D. degrees in Mechanical Engineering from The University of Michigan, Ann Arbor. His interests include stress analysis, nonlinear dynamics, structural vibration, and engineering design.

\section{Cory R. Davis, Oklahoma Christian University}

Robert Andrew Stevenson, Oklahoma Christian University

Robert Andrew Stevenson is a graduate level Engineering student at Oklahoma Christian University with a bachelors in Mechanical engineering from the same school. For his senior design project he and his team entered the regular class of the SAE Aero Design East competition and won first place in the presentation portion. After completing his masters he plans on entering into industry for a few years and then considering returning to school to pursue his doctorate degree. 


\section{Student Learning Modules in Trigonometry and Integral Calculus using LEGO MINDSTORMS® NXT}

\section{Introduction and Motivation}

Retention of engineering students continues to be a critical concern across the engineering disciplines $^{1-3}$. The typical engineering program begins with immersion of the student into the study of calculus. While this calculus content is mandatory to progression in the engineering disciplines, the abrupt transition from high school to Calculus I can be a deterrent to many students. Recognizing these facts, in fall 2009 the Oklahoma Christian University engineering programs implemented a new required freshman mathematics course, ENGR-1113 Foundations of Engineering Mathematics, which precedes Calculus I. This class was patterned on the pilot program at Wright State University entitled "A National Model for Engineering Mathematics Education" 4,5 . Both lecture and laboratory elements are utilized to engage a diverse group of student learners. The primary goals of the course are to improve student success, and thereby student retention, and to inspire students to see mathematics as the "language" of engineering rather than a segregated subject. Every effort has been made to make the laboratory modules fun for the students while maintaining the necessary rigor; acknowledging that learning begins with student interest and engagement ${ }^{6-8}$.

During the initial 2009 implementation of ENGR-1113, a set of rather traditional laboratory modules were utilized. Acknowledging that all engineering freshman at Oklahoma Christian University are required to take this class, lab assignments spanning electrical and mechanical engineering subjects were developed. The assignments were closely aligned with the lecture content and students typically received instruction on the material needed for each assignment no more than one week prior to completion of the lab work itself.

Feedback from the nearly 70 students that participated in the initial offering of ENGR-1113 indicated that, while the laboratories were functional, student engagement was not at the level desired. A concerted effort has been made during the 2010 implementation of the class, documented in this paper, to use more innovative and contemporary laboratory assignments to reinforce the math content. Two key changes were made to a subset of the laboratories. First, two of the laboratory assignments were rewritten to use the LEGO MINDSTORMS ${ }^{\circledR}$ NXT robotics kit. Second, one laboratory assignment was redesigned to incorporate computer data acquisition in lieu of manual data collection. The intent was to maintain the same mathematical focus of each assignment while utilizing more contemporary equipment during execution. It should be noted that at Oklahoma Christian University all incoming freshman receive a new Macbook computer as part of their tuition payments. As such, students are very anxious to utilize this new device within their academic work. The remainder of this paper will detail the changes made to the selected laboratory assignments and how these changes influenced student engagement within the class.

\section{Description of the Computerized Data Collection Enhancements}

Only one laboratory assignment was modified to add computerized data collection in lieu of manual data collection. The lab selected addresses Newtonian cooling and focuses on the 
fundamentals of first order differential equations (linear, constant coefficient only). This same laboratory assignment was also given during the inaugural offering of the ENGR-1113 class, but digital thermometers were used, requiring students to manually record the data. In the second offering, computerized temperature collection was implemented using the Vernier Go!Temp ${ }^{\circledR}$ product. In conjunction with the Vernier LoggerLite ${ }^{\circledR}$ software, packaged with each thermometer, the Go!Temp ${ }^{\circledR}$ device allows the students to directly collect the temperature of a hot cup of water to within $\pm 0.5^{\circ} \mathrm{C}$ at a rate of up to 2 samples/sec (far more than required for this experiment). It should also be noted that the data recorded by the LoggerLite ${ }^{\circledR}$ software is transferable to a range of data analysis packages for subsequent graphing and analysis. Within the ENGR-1113 course, MATLAB ${ }^{\circledR}$ was selected as the required tool and the transfer of data was managed by the freshman students.

While the addition of the computerized data collection was only a slight change to the lab, the students received the lab far more enthusiastically than when required to perform the manual data collection. Additionally, more data could be easily collected (i.e. faster sampling) to allow better comparisons to theoretical solutions of the first-order governing differential equation. Details of student response to the updated assignment will be discussed later in this paper.

\section{Description of the LEGO Mindstorms ${ }^{\circledR}$ NXT Enhancements}

The LEGO Mindstorms ${ }^{\circledR}$ NXT robotics kits are commercially available and provide a very nonthreatening robotics platform for freshman engineering students. Additionally, the LEGO Mindstorms ${ }^{\circledR}$ NXT-G programming language is extremely easy for students to learn. This is a critical factor as many of the students involved in this class have not yet completed a procedural programming course. Incorporating the robotics kit into the laboratory assignments forced considerable changes within the two selected assignments; though the mathematical focus of each remained unaltered.

The first laboratory assignment rewritten to integrate the LEGO Mindstorms ${ }^{\circledR}$ NXT robotics kit addresses trigonometry. This modified assignment requires students to navigate a maze of known configuration using the autonomous robot shown in Figure 1. This robot, equipped with treads, effectively rotates about a point allowing precise turns. This ability is critical if the students are to effectively use trigonometry to compute a path through the maze that will miss all obstacles.

The students begin by first calibrating both the linear and rotational motion of the robot. This calibration process, implemented using the LEGO MINDSTORMS ${ }^{\circledR}$ NXT-G programming language, is accomplished by systematically determining the duration the motors must be activated to move a specific distance and to turn a specific number of complete rotations. Once the students know the required durations for one value, linear scaling may be used to determine the value required for any other value. While certainly not the primary emphasis of this laboratory assignment, this linear scaling requirement effectively reinforces the instruction of algebra within the course and provides an excellent venue for discussing the power of linear techniques when they are valid.

Next, using trigonometry and line segments, each student team computes an optimized path through the maze which minimizes distance traveled. Figure 2 shows a map of the assigned maze. Students begin by essentially defining points on the map they wish for their robot to 
systematically reach. Connecting these points will result in successfully navigating the maze. Once the points are defined, the students compute the distance between each successive pair of points and the angle from each point to the next in the global reference frame. Finally, the students compute the relative turn angles required to travel along the lines connecting the points.

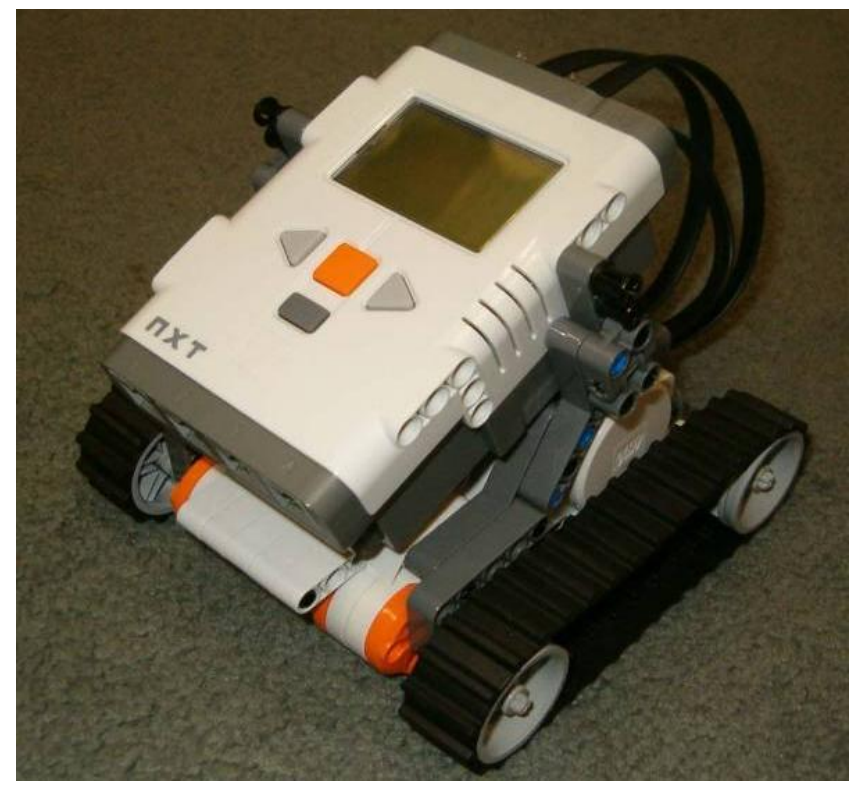

Figure 1: NXT robot used for the Trigonometry Laboratory Module.

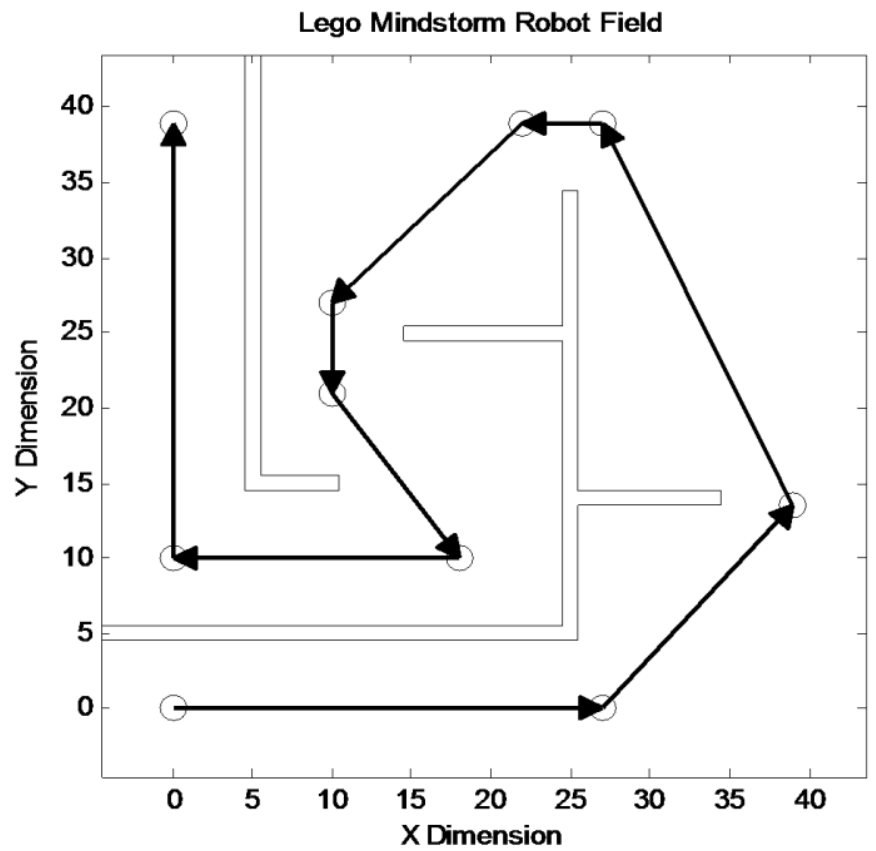

Figure 2: Playing field maze used for the Trigonometry Laboratory Module. 
Figure 3 presents the students navigating the actual maze. Note that the maze walls are only marked using tape for simplicity. The rule is clear; if the robot touches the tape the team must recalculate and try again. Additionally, the maze may be easily altered from year to year if desired.

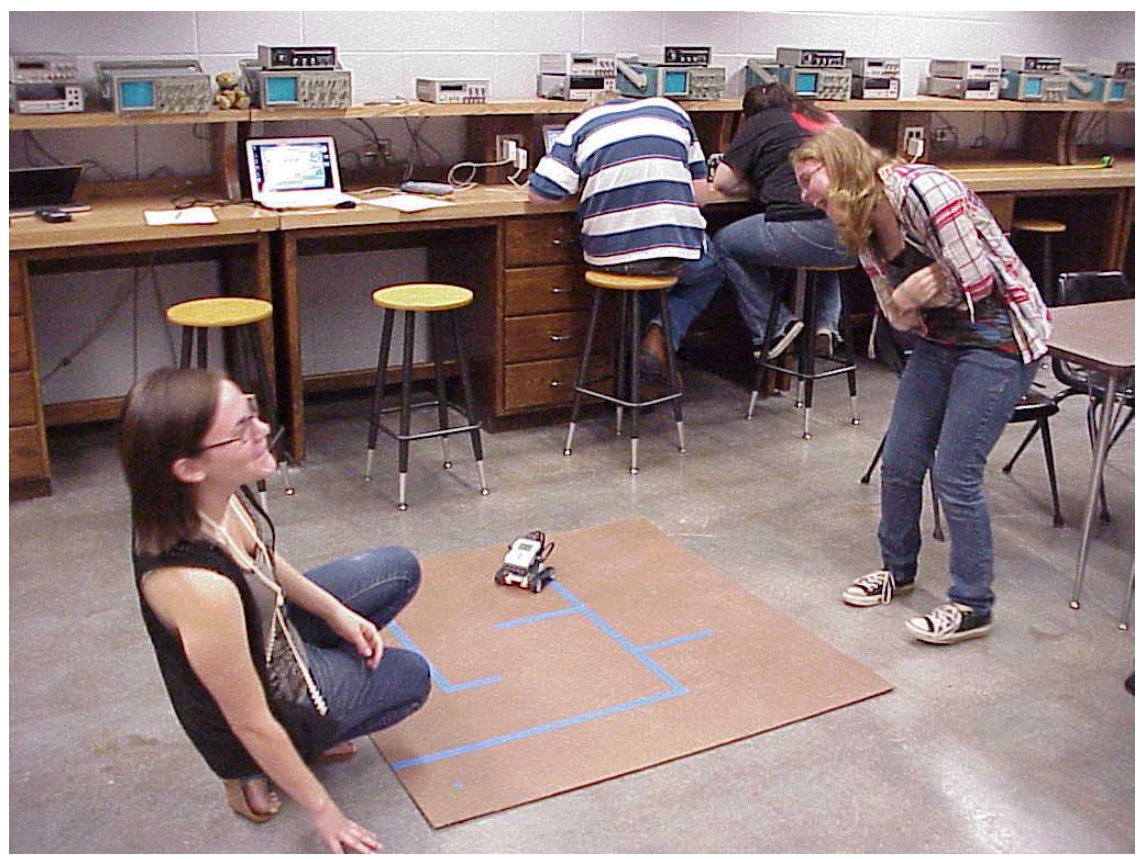

Figure 3: Robot maze used for the Trigonometry Laboratory Module.

Each student team must justify their solution mathematically for it to be considered valid. Navigating the maze by trial-and-error is not allowed. The supporting calculations must neatly include the tabulation of the segment lengths, absolute and relative angle computations, and to a lesser extent optimization checks (i.e. why does the team believe this is the shortest distance through the maze). To keep these computations manageable, a maze requiring only 9 to 10 straight segments to complete was selected.

One slight frustration that occurred during execution of this assignment was that the effective friction between the treads and the maze surface varied sufficiently to make precise turns difficult at times. When the robots spin in place, the treads must slip. Slight variations in the friction over the surface of the maze seemed to limit the accuracy of turns to approximately \pm 5 to 10 degrees. This issue is believed to be the result of both surface variations in the pressboard used for the maze and dust build-up during repeated use of the maze.

With a bit of perseverance, every student team was able to successfully program the autonomous robot to navigate the maze. Many were able to do so during the first attempt; the route being supported by calculation prior to the testing. Others had to iterate, some several times, to correct for calibration mistakes, trigonometry errors, and robot inconsistencies related to tread slippage. An educational strength of this assignment is that the students receive immediate visual feedback as to success or failure; though repeated failure associated with the prior mentioned inconsistencies caused moderate student frustration. 
The second laboratory assignment rewritten to utilize the LEGO Mindstorms ${ }^{\circledR}$ NXT robot kit focuses on integral calculus. This project requires the students to determine the area between the robot and an irregular wall as the autonomous robot travels along a defined track. Prior to execution of this assignment, the students receive instruction in the fundamental nature of integration. Specifically, the lectures focus on the fact that integration determines the accumulation of a quantity (in this case area) and that the integration process subdivides the domain of integration into smaller manageable sections. In the limit, as the number of subdivisions goes to infinity, the integral is reached.

A very similar robot chassis to that of the Trigonometry lab is used, shown in Figure 4, which is equipped with an ultrasonic distance transducer and wheels as opposed to the treads used earlier. The ultrasonic transducer measures the distance from the robot to the wall to an accuracy of approximately $1 \mathrm{~cm}$ and is a standard part of the LEGO Mindstorms ${ }^{\circledR} \mathrm{NXT}$ kit.

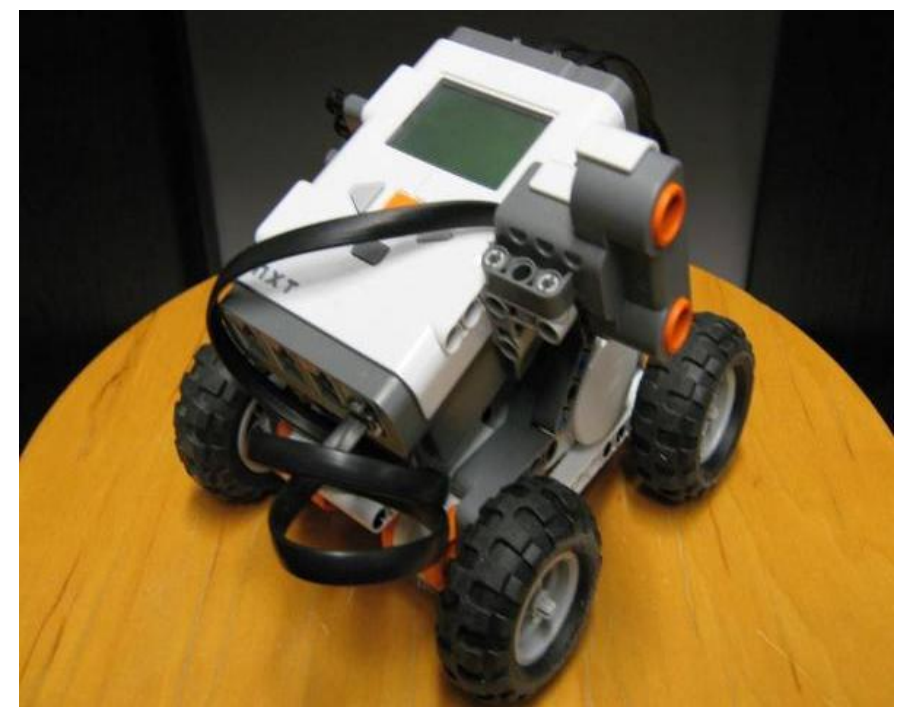

Figure 4: NXT robot used for the Integral Calculus Laboratory Module.

The robot travels a defined straight path while measuring and recording the distance between itself and the wall. The data is temporarily stored within the onboard memory of the NXT intelligent brick allowing the students to download the data to their laptop computer after each run. The "game field" for this assignment is shown in Figure 5 with a representative robot collecting data. The profile of the irregular wall is not critical and will likely be altered each year to "refresh" the lab. 


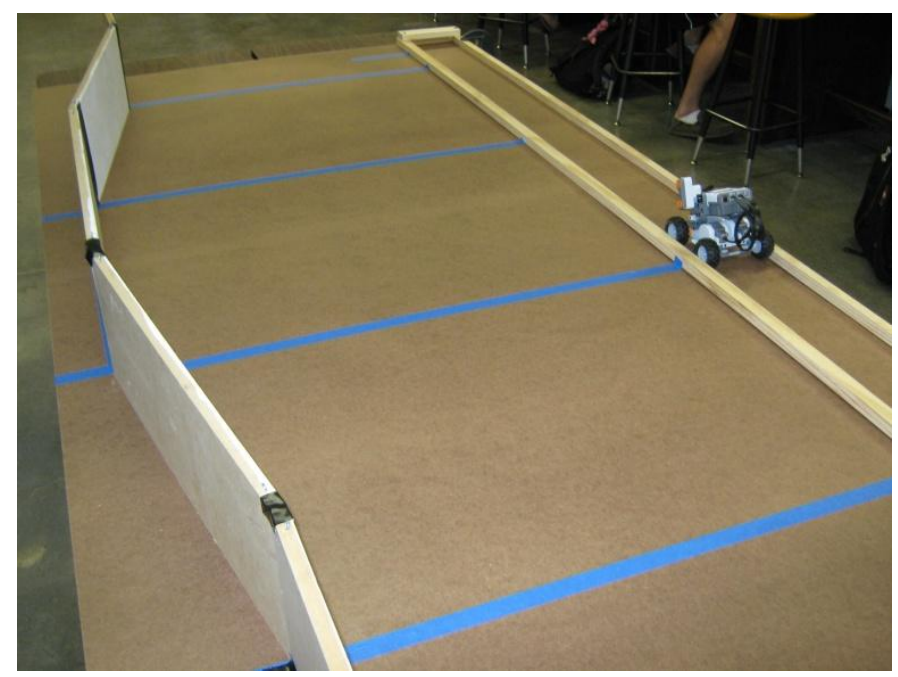

\section{Figure 5: Field used for the Integral Calculus Laboratory showing both the robot linear track and the "wall" defining the integral function.}

Each student team's robot traverses the field multiple times changing the number of measurements recorded along the path during each pass. By using these measured distances and the distance the robot moves between measurements, the students can use a trapezoidal rule to estimate the integral to varying degrees of accuracy. As can be seen in Figure 5, the playing field is also marked into large but well defined subsections to allow the students to manually measure and estimate the total area. This provides direct reinforcement that the integration process is indeed determining the area of the game field.

Fundamental to this laboratory assignment is the concept of convergence. As the students collect increasing amounts of ultrasonic data, in the limit the trapezoidal estimate converges to the true area (i.e. the value of the integral). For the wall shown in Figure 5, good integral estimates are possible with as few as 20 to 30 distance measurements. All the trapezoid area calculations are performed within the MATLAB ${ }^{\circledR}$ programming language; after the data collected by the robot is transferred to the student's laptop.

\section{Student Feedback}

After ENGR-1113 had concluded, students were asked to complete an anonymous survey about the class. Specific to the laboratory portion of the class, students were asked to rank the assignments from 1 to 10 (10 being the best) considering two aspects. First, each student ranked each lab as to if he/she found the assignment engaging (i.e. did the lab capture the students attention and motivate them to want to participate in the assignment). Second, each student ranked each lab as to if he/she found the assignment effective (i.e. did the lab significantly help reinforce the mathematical content each was targeted towards). Figure 6 shows the results of the ranking survey. 


\begin{tabular}{|c|c|c|}
\hline & $\begin{array}{c}\text { How } \\
\text { Engaging? } \\
\text { (Rank) }\end{array}$ & $\begin{array}{c}\text { How } \\
\text { Effective? } \\
\text { (Rank) }\end{array}$ \\
\hline Introduction to MATLAB Labs (Programming) & 1 & 3 \\
\hline Resistor circuits and Breadboard use (Algebra) & 4 & 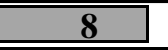 \\
\hline Parallel and Series Resistor Circuits Lab (Algebra) & $\$$ & 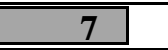 \\
\hline Lego Mindstorm Maze Lab (Trigonometry) & 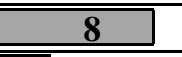 & 6 \\
\hline Properties and Manipulations of Sinusoids (Trigonometry) & 3 & 1 \\
\hline Two Loop Circuit Application of Systems of Equations (Matrices) & 2 & 2 \\
\hline Freefall Lab (Differentiation) & 7 & 4 \\
\hline Lego Mindstorm Ultrasonic Sensor Lab (Integration) & 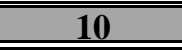 & 9 \\
\hline Newtonian Cooling Lab (Differential Equations) & 9 & $\overline{10}$ \\
\hline RC Circuit Lab (Differential Equations) & 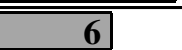 & $\$$ \\
\hline
\end{tabular}

Figure 6: Student ranking results for the ENGR-1113 Laboratory Assignments.

Examining Figure 6, the items with the largest data bars are the items most highly ranked by the students. Note that the three laboratory assignments modified between the first and second offering of the class to incorporate computer data acquisition and robotics were ranked as the most engaging or enjoyable labs, on average, by the class of 86 students. It is interesting to further note that the forth most engaging lab (an investigation of free fall) also utilizes computer data acquisition with an ultrasonic distance sensor. This free fall lab included data acquisition even in the initial offering of the class. As such, the data clearly supports that the students are more highly engaged when contemporary techniques and technologies are incorporated into the assignments.

The LEGO Mindstorms ${ }^{\circledR}$ NXT integration lab and the Newtonian cooling lab incorporating computer data acquisition were found to be the most effective labs in the view of the students. Students indicate these labs to be more than simply enjoyable, but also effective in reinforcing the class material. Conversely, the LEGO Mindstorms ${ }^{\circledR}$ NXT trigonometry was not found to be as effective as desired. Discussions with students indicate that the frustration with inconsistent turning of the robot (again believed to be the result of friction at the treads) deterred student learning. Modifications to the game field are planned to produce a more uniform friction surface. Additionally, adjusting the rate at which the robots turn, via program modifications, is being investigated to address the issue of non-uniform tread slippage.

At a higher level, the survey also asked students to comment on their perceived general impressions of the ENGR-1113 course. Figure 7 presents the results of these questions. Overwhelmingly the course was found to have a positive perceived impact. Of particular significance is the fact that over $80 \%$ of students either "agreed" or "strongly agreed" that the laboratory assignments aided in their understanding of the mathematics. This represents a significant value for this class relative to a traditional calculus sequence. 


\begin{tabular}{|c|c|c|c|}
\cline { 2 - 4 } \multicolumn{1}{c|}{} & $\begin{array}{c}\text { The lab sections aided } \\
\text { my understanding of the } \\
\text { lecture material. }\end{array}$ & $\begin{array}{c}\text { This course has increased } \\
\text { my motivation to study } \\
\text { engineering. }\end{array}$ & $\begin{array}{c}\text { This course has increased } \\
\text { my chance of success in } \\
\text { engineering. }\end{array}$ \\
\hline Strongly Agree & $\mathbf{3 7 \%}$ & $\mathbf{1 5 \%}$ & $\mathbf{1 6 \%}$ \\
\hline Agree & $\mathbf{4 6 \%}$ & $\mathbf{4 3 \%}$ & $\mathbf{4 9 \%}$ \\
\hline Neutral & $\mathbf{1 3 \%}$ & $\mathbf{2 5 \%}$ & $\mathbf{2 4 \%}$ \\
\hline Disagree & $\mathbf{4 \%}$ & $\mathbf{1 1 \%}$ & $\mathbf{9 \%}$ \\
\hline Strongly Disagree & $1 \%$ & $\mathbf{5 \%}$ & $\mathbf{1 \%}$ \\
\hline
\end{tabular}

Figure 7: Students' impressions of the value of the laboratory assignments.

\section{Conclusions}

ENGR-1113 Fundamentals of Engineering Mathematics at Oklahoma Christian University shows promise to be a very significant tool in combating the tide of both diminishing retention and motivation among freshman engineering students. Students are being provided the core math tools needed for success in their education through lectures that are tightly linked to laboratories that engage the students to want to learn. Specifically, contemporary techniques including computer data acquisition and autonomous robotics are being leveraged to make learning the mathematical principles fun. Student feedback clearly reveals the value of this firstyear experience in getting students off on the right foot in their education. Details of the laboratory assignments have been presented and interested parties are encouraged to contact the author for further information.

\section{Acknowledgements}

This work has been supported by the NSF Division of Undergraduate Education under the grant DUE-0817332 ${ }^{4,5}$. Any opinions, findings, conclusions or recommendations expressed in this material are solely those of the authors.

\section{References}

1. National Academy of Sciences (NAS), Committee on Science, Engineering, and Public Policy (COSEPUP), 2005, "Rising above the Gathering Storm: Energizing and Employing America for a Brighter Economic Future," Washington, DC: The National Academies press.

2. National Academy of Engineering, 2004, "The Engineer of 2020: Visions of Engineering in the New Century", National Academies Press, Washington, DC.

3. National Academy of Engineering, 2005, "Educating the Engineer of 2020: Adapting Engineering Education to the New Century", National Academies Press, Washington, DC.

4. Klingbeil, N. Rattan, K., Raymer, M., Reynolds, D. Mercer, R., Kukreti, A. and Randolph, B., 2007, “A National Model for Engineering Mathematics Education,” Proceedings 2007 ASEE Annual Conference \& 
Exposition, Honolulu, HI, June 2007.

5. Klingbeil, N. Newberry, B., Donaldson, A., and Ozdogan, J., 2010, "The Wright State Model for Engineering Mathematics Education: Highlights from a CCLI Phase 3 Initiative," Proceedings 2010 ASEE Annual Conference \& Exposition, Louisville, KY, June 2010.

6. Newberry, B. L., 2003, "Hands-on Learning in Engineering Mechanics using Layered Beam Design," Proceedings 2003 ASEE Annual Conference \& Exposition, Nashville, TN, June 2003.

7. Newberry, B. L., 2008, “Experimentally Determining Mass Moment Properties," Proceedings 2008 ASEE Annual Conference \& Exposition, Pittsburgh, PA, June 2008.

8. Newberry, B. L., 2008, “Investigating Impulse Loading using Model Rocketry," Proceedings 2008 ASEE Annual Conference \& Exposition, Pittsburgh, PA, June 2008. 